\title{
Study of Causes of Delayed Presentation of Decreased Vision in a Tertiary Eye Centre
}

\author{
Prof Manisha Rathi", MS, Dr. Dixit Soni, MBBS, Prof Sumit Sachdeva, MS, Dr. Jitender Phogat, MS, Dr. Ritesh Verma, MS
}

Regional Institute of Ophthalmology Pt Bd Sharma Pgims, Rohtak, Haryana, India

DOI: $10.36347 /$ sjams.2021.v09i01.030

| Received: 16.01.2021 | Accepted: 25.01.2021 | Published: 29.01.2021

*Corresponding author: Prof Manisha Rathi

\section{Abstract}

\section{Original Research Article}

There is a lack of awareness regarding the need for early presentation to the ophthalmologist to prevent visual disability or blindness. Conditions which are treatable with a good visual outcome with an early presentation and treatment can cause irreversible loss of vision if they are not treated in time. We studied 30 patients in our tertiary eye centre who presented late. The mean age of the patents was $64.13 \pm 9.28$ years. The female: male ratio was $2: 1$. Most of the patients had advanced primary glaucoma or secondary glaucoma. $21(70 \%)$ of them were illiterate and $24(80 \%)$ of them had a monthly income of $<$ Rs 5,000. The main reasons for presenting late were family issues and a lack of awareness. $22 / 30$ patients were from rural areas. $6(20 \%)$ patients were already blind at the time of presentation. Only $12(40 \%)$ had a good visual outcome of $6 / 12-6 / 6$ vision. This highlights the requirement for more outreach programs especially to rural areas and education regarding timely intervention for prevention of blindness.

Keywords: Neglected eye, POAG, ACG, PL, late presentation.

Copyright $(02021$ The Author(s): This is an open-access article distributed under the terms of the Creative Commons Attribution 4.0 International License (CC BY-NC 4.0) which permits unrestricted use, distribution, and reproduction in any medium for non-commercial use provided the original author and source are credited.

\section{INTRODUCTION}

Blindness due to cataract is a leading cause of treatable blindness in the world, with an estimated 36 million adults blind worldwide and 217 million with moderate or severe vision impairment in 2015. The main three causes of blindness globally were cataract, uncorrected refractive error, and glaucoma [1]. In India, blindness is $1.1 \%$, with the leading cause being cataract (62.6\%), which affects over 9 million people [2]. In developing nations, it has been observed that patients present late for cataract surgery. There are many factors which influence the late presentation of a patient. In a study, gender was one of the causes that played a role in seeking treatment at later stages of cataract [3].

Advanced cataract like hypermature cataract and lens-induced glaucoma are still seen in parts of India. These are more likely to develop in patients who have a good visual acuity in the fellow eye following previous cataract surgery. Delayed presentation can lead to a poor postoperative outcome, necessitating the education of the community about early presentation and surgery for cataract [4].

Studies about delayed presentation of cataract have mainly focused on lens-induced glaucoma. The reasons for delay in presentation have been studied which showed that lack of family support, lack of awareness, poor financial condition, acceptance of poor vision as a part of ageing, fear of surgery and associated systemic illnesses were some of the reasons. There is a requirement of more data about the proportion of late presenters of cataract and the factors associated with it [5].

In late presentation to the ophthalmologist with lens-induced glaucoma, it has been reported that the patients who were illiterate, older, and from rural areas were the worst affected. In a study, 30/50 patients got no visual improvement or minimal improvement in vision after the operation. This was attributed to a longer time lag or delayed presentation between development of symptoms of pain/redness and reporting for treatment [6].

\section{Material AND Methods}

Patients of more than 40 years of age who presented to our OPD more than 7 days after a vision threatening emergency or hypermature cataract were enrolled in this study. An informed consent was taken. A total of 30 patients were included, of which there were $20(67 \%)$ females and $10(33 \%)$ males. 
Manisha Rathi et al; Sch J App Med Sci, Jan, 2021; 9(1): 156-159

A detailed history taking was followed by a thorough ophthalmological examination including the uncorrected and best-corrected vision testing, slit lamp examination, CCT-corrected IOP measurement, and other tests as indicated.

Data including the age and sex, education level, family income, rural/urban residence, reason for delayed presentation, vision at presentation, diagnosis and final outcome were recorded and analysed.

\section{RESULTS}

The mean age of the patients was $64.13+9.28$ years. 21(70\%) of the patients were married, 7(23\%) were widows and $2(7 \%)$ were widowers. $17(56 \%)$ of the patients were homemakers, $9(30 \%)$ were farmers, $2(7 \%)$, were shopkeepers while 2 (7\%) were unemployed.

Table-1

\begin{tabular}{|l|l|l|l|}
\hline Age group & Male & Female & Total \\
\hline $41-50$ & 2 & 1 & 3 \\
\hline $51-60$ & 3 & 8 & 10 \\
\hline $61-70$ & 4 & 9 & 13 \\
\hline$>70$ & 1 & 3 & 4 \\
\hline TOTAL & $10(33 \%)$ & $20(67 \%)$ & 30 \\
\hline
\end{tabular}

The majority of the patients belonged to the female gender, $20(67 \%)$ of the total patients were females, while $10(33 \%)$ of the patients were males.

Table-2

\begin{tabular}{|l|l|l|}
\hline Education & No. & \% \\
\hline ILLITERATE & 21 & 70 \\
\hline UPTO 8TH STANDARD & 6 & 20 \\
\hline METRIC & 3 & 10 \\
\hline TOTAL & 30 & 100 \\
\hline
\end{tabular}

A large proportion of the patients, 21 (70\%) were illiterate.

\section{Table-3}

\begin{tabular}{|l|l|l|}
\hline Monthly family income & No. & \% \\
\hline < Rs 5000 & 24 & 80 \\
\hline > Rs 5000 & 6 & 20 \\
\hline TOTAL & 30 & 100 \\
\hline
\end{tabular}

The majority of the patients had a low socioeconomic status, with a monthly family income of $<$ Rs 5,000 per month.

Table-4

\begin{tabular}{|c|c|c|c|c|}
\hline Reason for late presentation/sex & Male n (\%) & Female n (\%) & Total & P-value \\
\hline $\begin{array}{l}\text { FAMILY ISSUES } \\
\text { NO ACCOMPANYING PERSON }\end{array}$ & $2(7)$ & $7(23)$ & 9 & \multirow{6}{*}{0.817} \\
\hline FEAR OF SURGERY & 1(3) & $2(7)$ & 3 & \\
\hline MONEY ISSUES & $2(7)$ & $1(3)$ & 3 & \\
\hline LACK OF AWARENESS & $2(7)$ & $4(13)$ & 6 & \\
\hline PP OTHER EYE- GOOD VN & $2(7)$ & $3(10)$ & 5 & \\
\hline $\begin{array}{l}\text { PERSONAL REASONS (SON MENTALLY CHALLENGED, } \\
\text { HOUSE BEING BUILT, MARRIAGE OF DAUGHTER, } \\
\text { SYSTEMIC ILLNESS) }\end{array}$ & $1(3)$ & $3(10)$ & 4 & \\
\hline TOTAL & 10 & 20 & 30 & \\
\hline
\end{tabular}

Among the males, the leading cause of late presentation was family issues, financial problems, lack of awareness and pseudophakia with good vision in the other eye. Among the female patients, the main causes were family issues, followed by a lack of awareness.

Table-5

\begin{tabular}{|c|c|c|c|c|}
\hline Reason/residence & Urban & Rural & Total & P-value \\
\hline FAMILY ISSUES & 3 & 7 & 9 & \multirow{7}{*}{0.528} \\
\hline NO ACCOMPANYING PERSON & & & & \\
\hline FEAR OF SURGERY & 0 & 3 & 3 & \\
\hline MONEY ISSUES & 0 & 3 & 3 & \\
\hline LACK OF AWARENESS & 3 & 3 & 6 & \\
\hline PP OTHER EYE- GOOD VN & 1 & 4 & 5 & \\
\hline $\begin{array}{l}\text { PERSONAL REASONS (SON MENTALLY CHALLENGED, HOUSE } \\
\text { BEING BUILT, MARRIAGE OF DAUGHTER, SYSTEMIC ILLNESS) }\end{array}$ & 1 & 3 & 4 & \\
\hline TOTAL & 8 & 22 & 30 & \\
\hline
\end{tabular}

Among the patients from the urban as well as the rural areas, the main cause for late presentation was family issues, followed by a lack of awareness. 
Manisha Rathi et al; Sch J App Med Sci, Jan, 2021; 9(1): 156-159

Table-6

\begin{tabular}{|l|l|l|l|l|}
\hline Reason/income & $<$ Rs 5000 & $>$ Rs 5000 & Total & P-value \\
\hline $\begin{array}{l}\text { FAMILY ISSUES } \\
\text { NO ACCOMPANYING PERSON }\end{array}$ & 8 & 1 & 9 \\
\hline FEAR OF SURGERY & 3 & 0 & 3 \\
\hline MONEY ISSUES & 3 & 0 & 3 \\
\hline LACK OF AWARENESS & 3 & 3 & 6 \\
\hline PP OTHER EYE- GOOD VN & 3 & 1 & 5 \\
\hline $\begin{array}{l}\text { PERSONAL REASONS (SON MENTALLY CHALLENGED, HOUSE } \\
\text { BEING BUILT, MARRIAGE OF DAUGHTER, SYSTEMIC } \\
\text { ILLNESS) }\end{array}$ & 3 & 1 & 4 \\
\hline TOTAL & & & \\
\hline
\end{tabular}

The patients from a lower socioeconomic status presented late due to mainly family issues, while those with a better financial condition presented late due to lack of awareness.

Table-7

\begin{tabular}{|l|l|l|}
\hline Vision at presentation & No. & \% \\
\hline $6 / 36-6 / 60$ & 2 & 7 \\
\hline$<6 / 60-3 / 60$ & 2 & 7 \\
\hline$<3 / 60-P L+$ & 20 & 66 \\
\hline PL- & 6 & 20 \\
\hline TOTAL & 30 & 100 \\
\hline
\end{tabular}

The vision at presentation was PL negative in $6(20 \%)$ of patients and $<3 / 60$ in $20(66 \%)$. Overall, the vision at presentation was markedly reduced in all patients.

Table-8

\begin{tabular}{|l|l|l|}
\hline Diagnosis & No. & \% \\
\hline PHACOMORPHIC GLAUCOMA & 8 & 27 \\
\hline ADVANCED ACG & 5 & 17 \\
\hline ADVANCED POAG & 5 & 17 \\
\hline HYPERMATURE SENILE CATARACT & 3 & 10 \\
\hline PHACOLYTIC GLAUCOMA & 2 & 7 \\
\hline NEOVASCULAR GLAUCOMA & 1 & 3 \\
\hline TRAUMA $2^{\circ}$ GLAUCOMA & 1 & 3 \\
\hline RD & 1 & 3 \\
\hline ABSOLUTE GLAUCOMA & 4 & 13 \\
\hline TOTAL & 30 & 100 \\
\hline
\end{tabular}

In our patients, the maximum number of patients had phacomorphic glaucoma, followed by POAG, advanced ACG, absolute glaucoma and phacolytic glaucoma. Thus, out of 30 patients, 26(87\%) patients had a form of primary or secondary glaucoma.

Table-9

\begin{tabular}{|l|l|l|}
\hline Visual outcome & No. & \% \\
\hline 6/6 TO 6/12 & 12 & 40 \\
\hline $6 / 18$ TO 6/60 & 6 & 20 \\
\hline$<6 / 60$ TO PL+ & 5 & 17 \\
\hline NO IMP IN VISION & 7 & 23 \\
\hline TOTAL & 30 & 100 \\
\hline
\end{tabular}

$12(40 \%)$ of the patients had a significant improvement in vision.

\section{Discussion}

In the present study on the causes of delayed presentation in vision threatening conditions/cataract, 30 patients who presented to our tertiary care centre were included. The mean age of the patents was $64.13 \pm 9.28$ years. The female: male ratio was $2: 1$, which is similar to a study conducted on patients with lens-induced glaucoma [7].

The main reason for late presentation in our study was family issues/ lack of an accompanying person, followed by lack of awareness. In a study from India including late presentation with glaucoma, awareness was very poor regarding glaucoma [8].

In our study the large proportion of patients presented late with lens induced and other forms of glaucoma. Late presenters of glaucoma have been shown to be from a lower socioeconomic class $[9,10]$.

Alarmingly, $6(20 \%)$ of our patients presented with no perception of light/ blindness. Most of the causes of blindness at presentation were preventable/ treatable if the patients had presented early. This stresses upon the need for more outreach programs and patient awareness. Late presentation with glaucoma has been shown in other studies as well [7].

The visual outcome in our study was good in only $12 / 30(40 \%)$ of our patients, highlighting that most of them had presented too late for restoration of vision. This has been seen in many studies, including one study that shows that a lack of awareness in a rural population about early treatment of cataract was a major factor in the visual status after cataract surgery. That study also showed that visual outcome and control of IOP following surgery was not satisfactory in $40 \%$ of patients due to late presentation of cases [6].

Most studies have shown that patients with a lower socioeconomic status and a lack of awareness present late to the ophthalmologist. The visual outcome is less than ideal if the patient presents late. Thus, we should aim at an increased awareness in the community about timely intervention for cataract and glaucoma and conduct more screening and outreach programs, which 
Manisha Rathi et al; Sch J App Med Sci, Jan, 2021; 9(1): 156-159

will go a long way to prevent permanent visual disability/loss of vision.

\section{Conclusions}

Late presentation of patients with cataract and glaucoma are more in the illiterate and patients who belong to a lower socioeconomic group. A poor visual outcome is seen in patients who present late. More screening and outreach programs are required to prevent permanent visual disability or blindness in late presentation.

\section{REFERENCES}

1. Sabanayagam C, Cheng C. Global causes of vision loss in 2015: are we on track to achieve the Vision 2020 target?. The Lancet Global Health. 2017;5(12):e1164-5.

2. Aarthi R, Roy G, Kar SS, Srinivasan R. Prevalence of cataract among adults above 50 years in a rural community of Villupuram, Tamil Nadu. Int J Adv Med Health Res. 2015;2:50-4

3. Tanchangya J, Khan RA, Bayasakh S, Wichaidit W. Gender disparity in delayed treatment-seeking behavior for cataract: 6 years of experience from impact Jibon Tari Floating Hospital. Asia-Pacific J Public Heal. 2015;27(2):240-7.

4. Hegde S, Sekharreddy M, Kumar M, Dayanidhi V. Prospective study of hypermature cataract in
Kanchipuram district: Causes of delayed presentation, risk of lens-induced glaucoma and visual prognosis. Kerala J Ophthalmol. 2018;30(3):187-92.

5. Karve S, Pimprikar S. Factors associated with late presentation of cataract in rural and urban patients: A cross-sectional study in Maharashtra. Indian $\mathrm{J}$ Clin Exp Ophthalmol. 2020;6(2):208-12.

6. Kothari R, Tathe S, Gogri P, Bhandari A. LensInduced Glaucoma: The Need to Spread Awareness about Early Management of Cataract among Rural Population. ISRN Ophthalmol. 2013;2013

7. Pradhan D, Hennig A, Kumar J, Foster A. A prospective study of 413 cases of lens-induced glaucoma in Nepal. Indian $\mathbf{J}$ Ophthalmol. 2001;49:103-7

8. Gogate P, Deshpande R, Chelerkar V, Deshpande $\mathrm{S}$, Deshpande $\mathrm{M}$. Is glaucoma blindness a disease of deprivation and ignorance? A case-control study for late presentation of glaucoma in India. Indian J Ophthalmol. 2011;59:29-35

9. Fraser S, Bunce C, Wormald R, Brunner E. Deprivation and late presentation of glaucoma: case-control study. BMJ. 2001;322:639-43

10. Ng WS, Agarwal PK, Sidiki S, L McKay, J Townend, A Azuara-Blanco. The effect of socioeconomic deprivation on severity of glaucoma at presentation. British Journal of Ophthalmology. 2010;94:85-7. 